\title{
Extraction and separation of molybdenum(VI) from acidic media by fatty hydrazides
}

\begin{abstract}
BACKGROUND: The increasing demand for molybdenum has encouraged the development of low-cost and environmentally friendly extractants to recycle and recover this metal. In the present study, solvent extraction of $\mathrm{Mo}(\mathrm{VI})$ from acidic media using a mixture of fatty hydrazides synthesised from palm olein as the extractant was carried out. The effects of various parameters such as acid, diluent, contact time, extractant concentration, metal ion concentration and stripping agent and the separation of Mo(VI) from other metal ions such as $\mathrm{Co}(\mathrm{II}), \mathrm{Ni}(\mathrm{II}), \mathrm{Al}(\mathrm{III})$ and $\mathrm{Mn}(\mathrm{II})$ were investigated. RESULTS: It was found that the extraction of Mo(VI) into the organic phase involved the formation of 1:3 complexes. Mo(VI) was successfully separated from commonly associated metal ions such as $\mathrm{Ni}$ (II), $\mathrm{Co}$ (II), $\mathrm{Al}(\mathrm{III})$ and $\mathrm{Mn}(\mathrm{II})$. Mo(VI) stripping from the loaded organic phase was studied using different acidic and alkaline solutions and was found to be optimal with ammonium hydroxide solution. CONCLUSION: These results are useful for the development of a method to recover Mo(VI) from acidic media utilising fatty hydrazides as the extractant.
\end{abstract}

Keyword: fatty hydrazide, solvent extraction, Mo(VI), separation, stripping 